\title{
QuASE faMosas (?): As ARIRANHAS COMO ESPÉCIE CARISMÁTICA NO TURISMO
}

\author{
Eveline Teixeira BAPTISTELLA*
}

RESUMO: O presente artigo tem como objetivo analisar a condição da ariranha (Pteronura brasiliensis) como espécie carismática no turismo do Pantanal Norte-MT a partir da sua representação midiática e da percepção de turistas sobre a espécie. A partir da metodologia de Análise de Conteúdo e de abordagem teórica interdisciplinar, analisamos a representação desses animais em documentários televisivos sobre o Pantanal. Tais evidências foram articuladas com dados obtidos em uma pesquisa de campo, na qual foram utilizadas técnicas etnográficas baseadas no referencial teórico da etnografia multiespécies. Concluímos que as ariranhas são representadas de forma positiva na mídia, mas que ainda se encontram em fragilidade quando se trata de sua participação em atividades turísticas, especialmente diante da possibilidade de conflitos com humanos.

PALAVRAS-CHAVE: Ariranha. Comunicação e cultura contemporânea. Escala sociozoológica. Estudos Animais. Pantanal.

Introdução

O presente artigo tem como objetivo analisar o processo de construção da imagem da ariranha (Pteronura brasiliensis) como espécie carismática no turismo do Pantanal Norte-MT. Situado num contexto de revisão das relações entre espécies que vêm ganhando relevo especialmente a partir dos anos 2000, este trabalho busca também, refletir sobre a convivência entre animais selvagens e humanos no contexto das relações de lazer. É importante ressaltar que se o turismo que envolve fauna silvestre em cativeiro é alvo de questionamentos, o mesmo não se pode dizer das atividades de observação de

\footnotetext{
* UNEMAT - Universidade do Estado de Mato Grosso. Faculdade de Ciências Sociais, Aplicadas e da Linguagem. Departamento de Jornalismo. Tangará da Serra - MT - Brasil. 78300-000 evelineteixeira@unemat.br. https://orcid.org/0000-0001-6292-3159.
} 
animais em liberdade, cujas implicações ainda são pouco discutidas e cuja regulamentação se faz necessária em âmbito nacional.

Através de um referencial teórico interdisciplinar que promove o diálogo entre sociologia, comunicação social, antropologia e estudos animais, propomos uma abordagem baseada em duas fontes de evidências: os documentários televisivos sobre vida animal que enfocam essa espécie de mustelídeo e a percepção dos turistas que realizaram atividades de observação de vida silvestre na região do Pantanal Norte (MT). No primeiro caso, utilizamos a metodologia de Análise de Conteúdo (BARDIN, 2016) e, na segunda etapa, nos baseamos na etnografia multiespécies (KIRSKEY \& HELMREICH, 2010; TSING, 2015; SUSSEKIND, 2018), utilizando ferramentas etnográficas para obtenção de dados.

A partir da etnografia realizada no âmbito do turismo no Pantanal Matogrossense foi possível identificar que, gradualmente, as ariranhas estão passando a fazer parte da lista de animais passíveis de serem observados durante as atividades desenvolvidas por turistas, especialmente as embarcadas. Nesse cenário, apesar de ainda não serem tão populares quanto as "espécies bandeira" da região, como o tuiuiú (Jabiru micterya) e a onça-pintada (Panthera onca), elas despontam como animais que os visitantes desejam ver e pelos quais manifestam sentimentos de fascínio, afetividade, além de intenso desejo de proximidade e até mesmo interação. Tal percepção demonstra uma mudança no status desses animais no imaginário popular, já que até o final do século passado apareciam na mídia associados à agressividade e eram temidos. Assim, nos propusemos a analisar como as ariranhas estão sendo representadas em documentários televisivos contemporâneos, e de que forma essas informações se refletem na consideração que recebem dos visitantes do Pantanal Norte-MT.

Na primeira parte do artigo, contextualizamos o turismo do Pantanal Norte-MT na atualidade e elaboramos um breve histórico sobre as ariranhas no imaginário popular, bem como da sua situação em termos ecológicos, estabelecendo a questão da hierarquização dos animais por meio da escala sociozoológica (ARLUKE E SANDERS, 1996). Na segunda parte, discutimos a representação das ariranhas a partir da metodologia de análise de conteúdo de documentários televisivos contemporâneos que têm o Pantanal como tema. Na terceira parte, nos detivemos nas informações obtidas em pesquisa de campo realizada durante a prática de atividades turísticas no Pantanal Norte-MT, na qual foram empregadas ferramentas etnográficas embasadas na etnografia multiespécies. Na quarta parte, apresentamos as considerações. 


\section{Ariranhas e imaginário}

O Pantanal Mato-grossense é uma das maiores áreas úmidas do Planeta, com um território de $160.000 \mathrm{~km}^{2}$ (MITSCH; GOSSELINK, 2007). Sua principal característica ecológica é o chamado "pulso de inundação", um regime anual de cheia e seca que determina variações na paisagem e na distribuição espacial dos animais não humanos. O bioma é considerado uma paisagem cultural, com pelo menos 100 anos de ocupação econômica, na qual a criação de gado bovino despontou como principal atividade produtiva (COSTA, 1999; FRANCO et al., 2013). No Brasil, se divide entre Mato Grosso e Mato Grosso do Sul e, hoje, tem no turismo uma de suas principais cadeias econômicas.

Na sua porção Norte, localizada em Mato Grosso, o turismo começou a se desenvolver a partir dos anos 1970, ainda sem infraestrutura e com predominância de estrangeiros. Naquele período, a caça era a atividade de "lazer" mais recorrente na região e a proposta de apenas observar os animais foi se consolidando a partir dos esforços de profissionais do turismo (BAPTISTELLA, 2020).

A parte de campo desta pesquisa foi realizada no âmbito da rodovia Transpantaneira, compreendendo o município de Poconé-MT, até a localidade de Porto Jofre-MT, entre 2016 e 2019. A região conta com uma grande variedade de hotéis, indo de um complexo turístico até pequenas pousadas e hotéis-barcos. As atividades oferecidas aos visitantes são bastante similares em todos os empreendimentos e gravitam em torno da observação de fauna: passeios em barcos e veículos adaptados, trilhas, mirantes e cavalgadas.

Entre um total de 59 turistas entrevistados, todos relataram que ver animais não humanos era um dos principais atrativos da viagem. A maioria deles declarou também que seu interesse em conhecer o bioma se deu a partir da mídia, em especial por meio de programas de TV. O encontro com os animais não humanos não é garantido, e essa característica é sublinhada no momento da compra dos pacotes. Assim, os turistas já sabem que há possibilidade de terem suas expectativas frustradas. Contudo, há animais que aparecem mais frequentemente e locais em que é mais fácil encontrar determinadas espécies.

Entre os habitantes mais famosos da região estão o tuiuiú, o jacaré-do-pantanal (Caiman yacare) e a onça-pintada. Os dois primeiros são de fácil visualização, especialmente na seca. Já o grande felino passou a ser objeto de passeios desde a década passada, quando um guia de Porto Jofre-MT e alguns pescadores, começaram a "cevar" os animais, ou seja, colocar comida em pontos estratégicos com o objetivo de habituálos aos humanos, garantindo sua aproximação (BAPTISTELLA, 2020). A partir da 
transmissão cultural de pais para filhos, hoje existe uma geração de jaguares acostumados com a presença de turistas embarcados e Porto Jofre-MT conta com uma infraestrutura voltada quase que exclusivamente para observação deles.

Nesse contexto, as ariranhas são animais com menor popularidade, sendo, inclusive, mais conhecidas entre os estrangeiros. Paula e Boulhosa (2015) afirmam que elas têm pouco potencial econômico para o turismo porque os avistamentos são difíceis. Ainda assim, a partir de entrevistas com sete guias da região, foi possível identificar que há um aumento no interesse em observá-las. Suas aparições também têm sido mais frequentes em determinadas regiões e a tolerância a humanos tem se ampliado em alguns bandos. Esses fatores facilitam sua ascensão como produto turístico. Na rodovia Transpantaneira, há hotéis que ofertam pacotes relacionados às ariranhas.

Se agora começam a se consolidar como espécie carismática, os mustelídeos foram, por muito tempo, associados majoritariamente a aspectos comportamentais ligados à agressividade e ferocidade em reportagens audiovisuais e impressas. O episódio de um homem morto ao pular num fosso de ariranhas no Zoológico de Brasília para salvar uma criança, em 1977, causou comoção nacional, repercutindo na imprensa de todo o país e marcando uma percepção pública negativa a respeito dos animais (VIDIGAL, 2017). Arluke e Sanders (1996) refletem sobre os papéis atribuídos aos animais não humanos a partir do conceito de escala sociozoológica. Para os autores, nosso grau de consideração pelos outros animais é uma construção social baseada inerentemente em julgamentos morais. Teríamos animais "bons" e "maus".

Os bons são aqueles tão domesticados e mansos que se submetem aos humanos. Estão divididos em duas categorias que se fundamentam na supremacia da nossa espécie sobre as outras formas de vida. A primeira é a dos animais de estimação, cuja subordinação se baseia no afeto. A segunda é a de ferramentas, constituída tanto por cobaias quanto por aqueles criados de forma industrial (ARLUKE E SANDERS, 1996).

Em outra ponta, temos os maus animais. Basicamente, aqueles que escapam do nosso controle e não se adaptam ao desejo humano de submissão absoluta. Eles constituem uma contestação à nossa autoridade.

Alguns animais, contudo, têm um problema com seu lugar na sociedade. Eles podem ser aberrações, cujo lugar é confuso, vermes, que não se confinam no seu lugar, ou demônios, que rejeitam seu lugar. Eles sãos esquisitices que causam repulsa, visitantes não desejados que provocam medo ou agressores perigosos que 
despertam horror. Por sua vez, a sociedade pode ignorar, marginalizar, segregar ou destruí-los ${ }^{1}$. (ARLUKE; SANDERS, 1996, edição eletrônica, tradução nossa).

No patamar mais baixo, viriam os demônios:

Abaixo dos vermes na escala sociozoológica viriam os piores animais comumente retratados na cultura popular como demônios, predadores ou comedores de homens - que contestam a própria ordem social estabelecida. Vermes podem se recusar a ficar no seu lugar inferior, mas os demônios representam um desafio mais sério e "maléfico" à maneira como as coisas "devem ser" por tentarem reverter o fundamento de relacionamento mestre-servo presente na ordem filogenética tradicional ${ }^{2}$ (ARLUKE; SANDERS, 1996, edição eletrônica, tradução nossa).

Animais que têm condições físicas de subjugar os humanos encontram seu lugar na categoria de demônios. É o caso das ariranhas que, num hipotético confronto com um ser humano, levariam a melhor. Conforme Costa (2016), essa escala é partilhada pela maioria dos indivíduos que fazem parte de uma cultura, mas também é flexível, a ponto de um animal poder transitar entre categorias. Para as ariranhas, a memória do ataque em 1977 detonou uma representação midiática que explorava aspectos comportamentais de ferocidade, sem que as causas da agressividade fossem contextualizadas.

Justamente pelos papéis de bom e mau serem posições fluidas, as ariranhas começaram a transitar também para o espectro de vítima dos humanos conforme o panorama de crise ecológica se agravou. Durante a década de 1980, a caça para retirada de peles quase dizimou a espécie. A curiosidade em torno delas também movimentou a captura para zoológicos e o tráfico, contribuindo para o declínio populacional da lontra gigante (RODRIGUES et al., 2018), sendo este o outro nome pelo qual as ariranhas são conhecidas. As medidas internacionais contra o comércio de peles e a regulamentação

\footnotetext{
${ }^{1}$ Some animals, however, have a problem with their plce in Society. They may be reaks that confuse their place, vermin that stray from their place, or demons that reject their place. They are oddities that cause repulsion, unwelcome visitors that provoke fear, or dangerous attackers that rouse horror. In turn, Society may ignore, marginalize, segregate, or destroy then [tradução nossa].

${ }^{2}$ Below vermin on the sociozoologic scale are the worst animals-commonly portrayed in popular culture as fiends, predators, or man-eaters-that contest the established social order itself. Vermin may refuse to stay in their lowly place, but demons mount a more serious and "evil" challenge to the way things "ought to be" by trying to reverse the fundamental master-servant relationship present in the traditional phylogenetic order [Tradução nossa].
} 
mais severa contra o tráfico foram positivas, mas a perspectiva de futuro para a espécie ainda é preocupante:

As principais áreas de ocorrência da espécie, Amazônia e Pantanal, serão diretamente impactadas pela construção de hidrelétricas de pequeno e grande porte em grande quantidade e no futuro próximo, prazo menor que 20 anos, o que equivale a três gerações da espécie, ocasionando uma representativa perda de habitat e provável alteração na comunidade de peixes, que são o principal recurso alimentar das ariranhas. Perdas populacionais também podem ocorrer devido a conflitos com pescadores comerciais e de subsistência e interferência da espécie na aquicultura, além da redução e poluição de habitat em decorrência de outros fatores (RODRIGUES et al., 2018, p.373).

Um levantamento do ICMBio (2018) mostra que a tendência é de que as comunidades de ariranhas continuem diminuindo. Somados aos fatores acima, a expansão da fronteira agrícola, a caça, o tráfico de animais silvestres e os incêndios florestais persistem como problemas que atingem as populações do mustelídeo. Hoje, ele é considerado espécie vulnerável, ou seja, enfrenta um alto risco de extinção (ICMBio, 2018). Segundo Rodrigues et al. (2018), atualmente não se sabe o tamanho populacional da espécie. Em entrevista concedida para esta pesquisa, a bióloga Caroline Leuchtenberger, pesquisadora do Instituto Federal Farroupilha e uma das maiores autoridades em ariranhas do mundo, estimou que existam no Pantanal um número de mil indivíduos reprodutores, o que é uma quantidade bastante baixa para uma espécie (Caderno de Campo, fevereiro de 2020).

Por isso, a ariranha tende a se beneficiar de uma mudança em seu status cultural, atingindo a posição de espécie carismática e, nos termos de Arluke e Sanders (1996), de "bom" animal. A construção desse papel passa por diversos fatores. Entre eles, o tipo de representação midiática que o animal recebe é fundamental para determinar como a espécie será considerada no imaginário popular (BAPTISTELLA, 2018). Daí a relevância de se discutir a caracterização contemporânea das ariranhas na imprensa.

\section{Um animal "de família"}

Os documentários televisivos, como visto acima, estão entre as principais fontes de informações que os turistas têm sobre o Pantanal. Assim, nos concentramos em programas que foram ao ar na década de 2010 para analisar a representação das ariranhas na mídia, a partir da metodologia de análise de conteúdo. Tendo como balizas 
as regras de exaustividade, representatividade, homogeneidade e pertinência (BARDIN, 2016), foram selecionados quatro programas. Dois episódios do Globo Repórter exibidos pela emissora aberta Globo - que trataram do Pantanal nos anos de 2011 e 2017, e dois episódios da série Brasil Secreto, Pantanal das Águas e Pantanal Selvagem - veiculados pelo canal por assinatura National Geographic - exibidos no ano de 2012 tanto no Brasil quanto na Europa e nos Estados Unidos.

Os programas tiveram seus textos transcritos e as imagens foram descritas brevemente para fins de análise. Cada episódio foi assistido sete vezes, num total de pelo menos 42 horas de contato com o material. Após a organização, foram feitas tabelas e a codificação, estabelecendo categorias de análise por temas, que foram interpretadas por inferência de dados qualitativos e quantitativos (HERSCOVICTZ, 2010). Assim, buscamos núcleos de sentido que trouxessem significações para a análise pretendida (BARDIN, 2016). Todos os animais citados nos vídeos foram elencados e suas participações divididas em três tipos: protagonista, coadjuvante e menção isolada. Os protagonistas foram os animais que tiveram mais características explicitadas nos programas ou maior tempo dedicado a eles. Os coadjuvantes tiveram menor exposição, mas, ainda assim, receberam citações relevantes que permitem inferências. As menções isoladas tratavam de animais que apareceram menos de três vezes e em referências pontuais, servindo como elementos de ilustração.

Observamos como os episódios tratavam as características físicas dos animais não humanos, tais como aparência, força e porte. Depois, selecionamos as referências aos serviços ecológicos prestados pelos animais não humanos, tais como dispersão de sementes. Este quesito é importante porque há várias espécies que só são protegidas devido ao seu valor econômico, e o critério de serviço ecológico é uma corrente que justifica a preservação a partir dos benefícios que o animal presta para o ecossistema. Considerando que inteligência e consciência podem ser demonstradas a partir de todas as ações apresentadas nos vídeos analisamos as características comportamentais, de forma a inferir como foram descritas as capacidades intelectuais e a subjetividade das espécies retratadas. Este último item foi composto de duas variáveis:

1. Relacionamentos - composto por menções a comportamentos de cuidado parental, interação intra e extra específica, reprodução, transmissão de conhecimento e formas de comunicação. Tais itens permitem trabalhar com alguns conceitos-chave dos estudos animais: os animais não humanos têm estados emocionais tão complexos quantos os nossos (BEKOFF, 2010; KING, 2014), têm culturas próprias (LESTEL, 2001) e podem adotar atitudes que Waal (2010) classificou como pilares da moralidade, tais como capacidade de empatia, reciprocidade e senso de justiça. 
2. Estratégias de sobrevivência - Trata de temáticas ligadas à alimentação e aos modos como os animais não humanos conduzem seu cotidiano de forma a sobreviverem.

Elencamos o status dos animais não humanos em relação ao ambiente e às ações antrópicas: raros, frágeis e/ou em extinção. A menção de periculosidade para os humanos também foi avaliada, pois são temas que costumam ecoar entre os turistas, determinando a valorização/desvalorização da espécie. Por fim, buscamos verificar se os animais não humanos enfocados nos programas tiveram seu comportamento delineado a partir de uma escala de valores morais humanos. É preciso pensar aqui nos próprios conceitos que nos separam das outras espécies. É certo que união familiar, transmissão de conhecimento e a proteção aos mais frágeis do grupo são características nossas, mas não há por que imaginar que não sejam também de outros bichos, conforme demonstram Bekoff (2010) e King (2014).

Não falamos em antropomorfização propriamente, pois acreditamos que o conceito pode resvalar no especismo. Conforme Bekoff e Pierce (2009), antropomorfismo é simplesmente a atribuição de características humanas a animais. No entanto, a aplicação do termo pode variar bastante. Uma crítica comum a programas de TV e documentários é justamente que eles antropomorfizariam os animais. Comparar o desenho do rosto de uma arara-azul e dizer que ela está sorrindo, por exemplo, pode facilmente ser classificado como projeção. Mas quando se trata de emoções demonstradas por gestos e atitudes, até mesmo olhares, as classificações começam a se complicar. Muitas vezes, nos programas televisivos, quando um animal é mostrado brincando com seus companheiros ou realizando um gesto de comunicação, isso pode ser apresentado como antropomorfização. Assim, como se referir aos filhotes de um grupo como bebês. Afinal, para o senso comum - que, felizmente, vem se reduzindo tudo isso seria próprio apenas dos humanos. Contudo, os conhecimentos que temos hoje, tanto científicos quanto adquiridos a partir da convivência com os outros animais, demonstram facilmente que afetividade, comunicação, inteligência, senso moral e outras características que já foram apontadas como distintivas da raça humana, na verdade, estão distribuídas entre as espécies.

Ainda no século XIX, Darwin (2009) defendia a continuidade mental entre seres humanos e os demais animais. Ele apontava que estes eram dotados de capacidades cognitivas bem como possuíam subjetividade. Afinal, se somos todos animais e se nós seríamos o "ápice” de uma linhagem evolutiva, é muito mais razoável crer que emoções e certos comportamentos surgiram muito antes de nós e são encontrados em diferentes animais (LESTEL, 2001; BEKOFF, 2010). Cuidado parental, carinho e até mesmo a capacidade de enganar não são exclusividades nossas (LINDEN, 1999). Daí, a posição 
de verificar se os programas atribuem aos animais comportamentos morais valorizados (ou não) nas sociedades humanas ocidentais contemporâneas - nas quais os shows são exibidos - em vez de optar por uma investigação que trabalhasse com o conceito de antropomorfização.

Tanto o Brasil Secreto (BS) quanto o Globo Repórter (GR) são classificados, de acordo com Souza (2004), como produtos televisivos da categoria Informação e fazem parte do gênero Documentário. São programas que apresentam temas de forma aprofundada, com abordagem crítica e que teriam um compromisso em "[...] levar ao telespectador uma visão do mundo, da realidade de outros países e de outras culturas" (SOUZA, 2004, p.145). Serafim (2009) pontua que a relação entre documentário e televisão pode ser ambígua e conflituosa. O autor destaca que no sistema de classificação das emissoras de TV, "[...] qualquer produto que aborde o real e que ultrapasse os 15 minutos de duração é denominado como documentário" (SERAFIM, 2009 , p.55). Por isso, o formato dos programas analisados é bastante diferente. Enquanto o BS se afilia ao modelo de documentário clássico, o GR utiliza os padrões de reportagem telejornalística. A partir de Nichols (2012), podemos entender porque dois produtos tão diferentes podem ser considerados como participantes de um mesmo gênero.

Os documentários não adotam um conjunto fixo de técnicas, não tratam de apenas um conjunto de questões, não apresentam apenas um conjunto de formas ou estilos. Nem todos os documentários exibem um conjunto único de características comuns. A prática do documentário é uma arena onde as coisas mudam. (NICHOLS, 2012, p.48).

As ariranhas surgem como protagonistas em três dos quatro episódios analisados. São destaque em Pantanal das Águas (2012), na série Brasil Secreto, e nos dois episódios do Globo Repórter. No programa produzido pelo National Geographic, apesar de o plot $^{3}$ orbitar em torno da luta pela sobrevivência, é justo dizer que o arco dramático das ariranhas gira em torno dos temas de comportamento, especialmente da vida familiar. Ao longo da narrativa, a palavra "família" aparece 10 vezes e em todas elas, está associada aos mustelídeos. Apesar de correrem risco de extinção, elas são classificadas apenas como animais raros e não há nenhum posicionamento em relação a serviços ecológicos prestados pela espécie. O episódio trata o Pantanal como um lugar

\footnotetext{
${ }^{3}$ Conforme Rey (1989, p.22), o plot é a alavanca da trama, seu drama principal: "Toda história tem seu núcleo, seu ponto central, donde partem as demais tramas e intrigas. Plot é a ação principal, geradora de conflitos secundários".
} 
isolado e não há nenhuma representação de tipos humanos nem referência a prejuízos sofridos pelas ariranhas em decorrência de ações antrópicas. Elas aparecem como frágeis apenas diante das oscilações climáticas e tem como antagonistas apenas sua principal predadora, a onça-pintada.

Fisicamente, as ariranhas são descritas pelas mandíbulas e dentes afiados e pelo tamanho - são as maiores lontras do mundo, daí a denominação alternativa de lontra gigante, que é também a tradução literal de seu nome em inglês, giant otter. Sua ferocidade é reforçada, mas de forma contextualizada: ligada a atos que envolvem a segurança e sobrevivência dos membros do seu grupo bem como a defesa do território, diminuindo a possibilidade de inferir que sejam perigosas para os humanos. O roteiro as apresenta como integrantes de uma família agitada, cuja maior prioridade é a defesa da cria. Os adultos são capazes de arriscar a vida pelos mais novos. Há cenas em que indivíduos adultos voltam para socorrer um filhote perdido e atacam uma onça-pintada. Segundo o roteiro, os jovens são tratados como "preciosos" por seus progenitores. É possível inferir que os mais velhos são responsáveis não apenas pela alimentação e segurança da prole, mas também pela transmissão dos saberes necessários à vida no Pantanal: o texto afirma que viverão um ano e meio com este grupo até que iniciem seu próprio núcleo familiar - movimento que acontece quando os mais velhos se dispersam pela bacia em busca de peixes, encontrando oportunidade de formar sua própria comunidade. Para delinear o relacionamento entre a espécie, o termo "bando" nunca é utilizado, elas são sempre tratadas como integrantes de famílias.

A partir da caracterização dos relacionamentos dos mustelídeos é possível inferir a existência de emoções tidas como "complexas", como afeto e solidariedade. É salientado o aspecto lúdico da convivência familiar: elas correm, pulam, mergulham, rolam umas sobre as outras e chegam a interagir com uma câmera. São registros que revelam os animais se divertindo e que contam com uma trilha sonora mais leve, que dá o tom de brincadeira. Da mesma forma, o ócio aparece como parte da rotina: vemos os mustelídeos descansando por causa do calor intenso.

A utilização de padrões de comportamento valorizados por humanos é constante. Não apenas as ariranhas são classificadas como famílias, mas os mais jovens são tratados como "bebês" no texto e há uma passagem em que os hábitos alimentares são chamados de "etiqueta familiar". Se não há trechos citando a inteligência delas de forma expressa, podemos encontrar muitas informações que confirmam tal premissa a partir da comunicação e das estratégias de sobrevivência. Ao longo do programa é possível realmente ouvir a "voz" das lontras gigantes. Suas vocalizações são constantes nas cenas e até mesmo os filhotes se utilizam desse vocabulário para, por exemplo, pedir por socorro, demonstrando a existência de um código de comunicação sistematizado. 
Algumas estratégias de sobrevivência também indicam coordenação e capacidade de planejamento. Os pais cavam tocas em locais diferentes para o caso de precisarem se mudar rapidamente devido ao surgimento de um predador na região em que vivem. A migração também é adotada para garantir a alimentação no caso de falta de peixes. Além disso, elas agem de forma a maximizar a pesca: encurralam os peixes nas partes rasas e reviram o leito do rio, para encontrar possíveis animais escondidos.

Para completar, há o registro de cooperação com as aves conhecidas como biguás: ariranhas e aves empurram os peixes umas contra as outras para facilitar a pesca. Há mais demonstrações de convivência pacífica com outas espécies. As saracuras comem os restos de peixe próximos às tocas sem problemas. Na época de fartura, as ariranhas passam pelos jacarés-do-pantanal sem que ambos se incomodem. $O$ documentário traz a percepção de que elas só se confrontam com outras espécies em caso de necessidade, reafirmando a percepção de que a agressividade é um recurso utilizado apenas quando é preciso. Os mustelídeos encontram diferentes meios de desestimular embates, como vocalizações e movimentos corporais.

Em resumo, as ariranhas são representadas como animais com laços familiares fortes, que primam pela união. As características físicas destacadas (sentidos e morfologia) demonstram que o mustelídeo é capaz de matar, e sua ferocidade e agressividade são evidenciadas. Entretanto, no conjunto da obra, fica o contraste com os laços familiares sólidos, afetividade extrema e inclinação a afugentar as ameaças em vez de entrar em embates. Temos ainda, um conteúdo que trabalha os animais como indivíduos, mas que, ao generalizar os comportamentos, acaba reforçando o conceito de espécie como uma "camisa de força", que limitaria animais iguais a se comportarem de forma semelhante.

Os dois episódios do Globo Repórter em que as ariranhas surgem como protagonistas seguem o estilo jornalístico e, com isso, a presença humana faz parte da narrativa. Em ambos os episódios, a fonte sobre os mustelídeos é a pesquisadora Caroline Leuchtenberger, que dialoga com a repórter, apresentando informações sobre a espécie.

No programa exibido em 2011, a lontra gigante recebe um retrato muito aprofundado. Há grande quantidade de informações bem como cenas do mustelídeo em liberdade. A ampla variedade de imagens contribui para que a reportagem aborde mais aspectos comportamentais. O fio narrativo, novamente, é a vida familiar, valorizando a noção ocidental de família nuclear. Elas são apresentadas como animais fortes dentro do ecossistema, mas frágeis diante das ações antrópicas. $\mathrm{O}$ fato de estarem em processo de extinção também é destacado. Não há menção de serviços ecológicos prestados pelos animais. 
Apesar da ferocidade evidenciada, elas não são representadas como perigosas para os humanos. Fisicamente são caracterizadas pelo fato de terem "identidade". A mancha branca no pescoço é única de cada indivíduo e é possível diferenciá-las. Alguns animais possuem chips transmissores e, por isso, o grupo não apenas é facilmente localizável como também tem integrantes que são conhecidos dos pesquisadores. Mesmo assim, o comportamento do bando é estendido a todas as ariranhas, caracterizando a noção de espécie que não tem variações individuais de condutas.

Apresentadas como arredias e ariscas, elas aparecem em imagens de brincadeiras, caça, marcação de território, descanso, alimentação, vocalizações e até em um embate contra um jacaré-do-pantanal. $\mathrm{O}$ aspecto lúdico aparece não somente em cenas que evocam brincadeiras, mas também no texto, que afirma serem as jovens ariranhas bichos que gostam de brincar. A organização familiar ressalta a divisão de poderes, com macho e fêmea dominantes. A matriarca comanda as ações do grupo, estabelecendo quais atividades serão feitas e em quais momentos, enquanto o patriarca protege o bando de invasores e garante a segurança de todos. O cuidado parental é tratado com expressões que aproximam o cotidiano das ariranhas de hábitos adotados por famílias humanas e reforça a noção de transmissão de conhecimento. Nesse espectro, a comunicação é outro aspecto valorizado. A matéria demonstra que elas têm uma linguagem própria e várias cenas exibem os mamíferos vocalizando, detalhando que os pesquisadores já documentaram tipos sonoros utilizados pelos mustelídeos e são capazes de identificar o que cada um significa. Assim como em Brasil Secreto, o ataque é apontado como o último recurso na manutenção da sobrevivência do grupo. Todo um arsenal de comportamentos dissuasivos é detalhado na obra: desde a marcação de território até as vocalizações e gestuais ameaçadores.

A representação das ariranhas no contexto do programa é de animais de forte união familiar e dotados de inteligência bem como de afetividade. O roteiro explora bastante as semelhanças com padrões culturais humanos. Há muitas informações que mostram o quanto elas podem ser parecidas conosco: além da vida em família, são dotadas de linguagem própria e o fim da fase reprodutiva da vida, a menopausa, marca transformações no status social das fêmeas.

No episódio do Globo Repórter de 2017, o gancho que garante a posição de protagonistas às ariranhas é a linguagem. A matéria traz uma grande gama de informações ligadas ao comportamento da lontra gigante. A agressividade das ariranhas é evidenciada - brigam com intrusos e até mesmo com companheiros de bando que tentam roubar seu alimento. Há imagens de um grupo perseguindo ferozmente um animal que não pode ser identificado. No entanto, elas não são tratadas como risco para os humanos. Mais uma vez, é descrito que buscam afastar indivíduos com um 
comportamento que inclui signos verbais e não verbais. Ou seja, de acordo com a produção fílmica, evitam confrontos.

As características físicas dos mustelídeos não são trabalhadas no roteiro. $\mathrm{O}$ ser humano volta a surgir como grande inimigo. Caça e perda de habitats são responsáveis pela entrada na categoria de em risco de extinção. Aí entra também o critério de raridade. A repórter afirma que existem poucos lugares no Brasil em que eles ainda podem ser vistos. As ariranhas são ligadas a serviços ecológicos, pois é citado que são indicadores de qualidade ambiental - condição que a repórter relaciona à inteligência dos animais. Outro trecho que permite inferir inteligência dos indivíduos é a articulação de tipos sonoros, formando um vocabulário. A jornalista ilustra a comunicação fazendo comparações com padrões humanos, ao dizer que ariranhas "falam".

Não são apontados dados sobre transmissão de conhecimento, mas uma câmera escondida em um abrigo revela o extremo cuidado parental da espécie com os mais novos. Se a unidade familiar é menos evidenciada, o episódio destaca aspectos que demonstram que são animais que não apenas possuem inteligência como também tem linguagem própria, utilizada de forma complexa para resolver problemas do cotidiano. O texto utiliza expressões que podem aproximar comportamentos de ariranhas e de humanos, mas no fim, o tratamento reservado é o de espécie.

Para Motta (2007), o conjunto de informações transmitidas pela mídia a respeito de certo assunto se transmuta do real para o imaginário, indo formar uma grande narrativa que adere ao corpo simbólico de nossa cultura. DeMello (2012) identifica que, graças à tecnologia, hoje é possível observar e registrar de forma mais apurada o cotidiano dos animais. Por isso, a produção documental deste século traz obras que tiram os animais da posição de substitutos para a figura humana e trata de seus hábitos de forma a ampliar o conhecimento sobre as demais espécies. A partir dos dados obtidos nos programas verificamos que a representação das ariranhas nos produtos audiovisuais traz uma nova forma de retratar os animais, muito conectada a seus valores intrínsecos. A agressividade e ferocidade são tratadas como recursos extremos de defesa e não como características dominantes das lontras gigantes. Elas também não aparecem como criaturas perigosas para a espécie humana. Inclusive, nos dois episódios do Globo Repórter é o ser humano que fica com o papel de besta perigosa, cujas ações são capazes de dizimar outras espécies.

Assim, a partir da adaptação dos procedimentos da análise pragmática da narrativa jornalística (MOTTA, 2007), podemos dizer que os três programas formam uma linha de representação que posiciona as ariranhas como animais com fortes laços familiares e grande capacidade de união e organização. Seus comportamentos são abordados a partir de um viés moral humano, e é clara a transferência, para o bem ou 
para o mal, do conceito ocidental de família para os mustelídeos. No entanto, tudo é tratado como natural, sem que a vida interior e as capacidades cognitivas das ariranhas sejam apontadas como algo surpreendente.

O tratamento de espécie aparece principalmente pela forma como os programas estendem o comportamento de um grupo a todos os outros. Contudo, as narrativas contemplam os animais como seres inteligentes e dotados de subjetividade, sem que haja nenhuma menção a "instinto". Sua condição de animais complexos e conscientes é evidenciada a partir da representação das relações de grupo, que incluem brincadeiras, transmissão de conhecimento e trocas comunicacionais comparáveis às humanas. Os serviços ecológicos, provavelmente, só aparecem em um único episódio justamente porque as narrativas optam por destacar as informações sobre hábitos e costumes, fugindo de uma representação que os ligue à perspectiva de "produtos". Por fim, vale dizer que as ariranhas aparecem nos três programas como animais raros, enquanto o conceito de espécie em extinção é apontado apenas nos dois episódios do Globo Repórter.

A atribuição aos animais não humanos de características que costumam ser consideradas exclusivas de nossa espécie provoca identificação e empatia. Isso contribui para que sejam vistos sob uma ótica mais favorável. É válido, então, resumir que o conjunto dos episódios constrói uma representação dos mustelídeos majoritariamente como seres inteligentes, conscientes, dotados de afetividade e de comportamento moral conforme definido pela etologia cognitiva, ou seja, capazes de atos de cooperação, reciprocidade, empatia e altruísmo, entre outros (BEKOFF, 2010).

\section{De feras a belas}

Podemos dizer que a representação das ariranhas nos documentários televisivos permite despertar a empatia nos humanos, na medida em que os animais são afiliados a valores e comportamentos que são vistos positivamente, em especial no modelo de sociedade ocidental baseado no hiper-consumo (BAUMAN, 2008). Isso nos ajuda a entender o tipo de consideração que os turistas têm pelas lontras gigantes. Thompson (2011) afirma que a mídia criou a "mundanidade mediada", ou seja, a maneira como interpretamos o mundo, especialmente o que está fora do alcance da experiência pessoal, passa a ser modelado pela mediação de formas simbólicas. Além disso, conforme Martín-Barbero (2003), a televisão é um veículo que provoca identificação entre seus telespectadores e funciona na formação de um imaginário coletivo. 
No contexto do turismo, Urry e Larsen (2014) pontuam o papel central da TV na cultura pós-moderna e lembram que os meios de comunicação de massa transformaram o olhar do turista, que se tornou conectado com os enquadramentos de outras práticas sociais e culturais. Para os autores, o próprio turismo teria perdido sua característica aurática, nos termos estabelecidos por Walter Benjamin, tornando-se mais uma instância marcada pela repetição a partir de padrões pré-configurados. Assim, na fase de campo, identificamos que os visitantes já traziam de casa uma "memória" das ariranhas, memória essa criada a partir das imagens e textos que tratam dos animais na mídia.

Durante a pesquisa de campo, foi verificado que as pessoas com menos de 35 anos demonstravam interesse em ver o animal não apenas por sua beleza, mas também por suas características comportamentais - conhecimento que obtiveram pela imprensa. Já entre os turistas acima dos 40 anos e, em especial os idosos, a memória do ataque no zoológico de Brasília coexistia com um imaginário mais recente, consolidado a partir de novas informações sobre os animais. Assim, era costumeiro que declarassem que as ariranhas são ferozes, mas somente se forem ameaçadas - um discurso que os guias também repetem incessantemente. Conforme um dos entrevistados: "É um animal amorosíssimo com a família. Se protegem, se cuidam. O que aconteceu [no zoológico] foi um acidente, uma defesa. A ariranha se defende. Se alguém pula no seu quintal, você também vai reagir. Fora isso, é um animal muito especial, muito inteligente" (Caderno de Campo, julho de 2018).

Outro ponto importante é que os turistas que fizeram parte dessa pesquisa se mostraram mais interessados em encontrar espécies que sejam consideradas raras e/ou em extinção. Apesar de as duas categorias serem distintas, para os visitantes elas se imbricam e determinam, inclusive, a resposta em relação a um determinado avistamento. Eles tendem a reagir de forma mais emotiva quando estão diante de um animal que está ou que julgam estar em processo de extinção. Também dedicam mais tempo observando os animais não humanos que consideram estar em tal condição, da mesma forma que valorizam mais as lembranças desses encontros.

Assim, os humanos que chegam ao Pantanal já não temem mais as ariranhas. Pelo contrário, desejam vê-las tanto por que passaram a admirá-las quanto porque pode ser que, muito em breve, não existam mais. Elas assumiram o papel de bons animais primeiramente porque a narrativa a seu respeito as posiciona sob uma ótica que os humanos aprovam. "O lugar dos bons animais, sejam eles humanos ou não humanos, é claro na ordem social. Eles participam como uma espécie de "cidadãos decentes" por 
serem confiáveis, previsíveis e obedientes aos papéis que lhes foram atribuídos ${ }^{4}$ (ARLUKE; SANDERS, 1996, edição eletrônica, tradução nossa.).

As ariranhas que aparecem na televisão são unidas, cuidam abnegadamente dos mais frágeis e possuem uma estrutura social baseada na cooperação. Elas brincam, se divertem, mas não deixam de obedecer a códigos de conduta estabelecidos por seu grupo. Também mantêm um comportamento harmonioso com a maioria das espécies do entorno. A agressividade é um componente marginal, que se manifesta só em casos de necessidade. E que pai humano não levantaria a voz para proteger seu filho ou se mobilizaria para afastar agressores? Além disso, a ideia de que estão em extinção reforça a noção de que estão totalmente subjugadas pelos humanos. Mais do que isso, desperta nos turistas a percepção de que são frágeis e merecedoras de proteção. Assim, de feras ameaçadoras e matadoras de humanos, elas passaram a ser vistas como animais dignos de simpatia, admiração e, o principal, proteção. A maioria dos turistas manifestou tais sentimentos e o desejo de observá-las. Contudo, permanece a premissa de que são avessas a humanos e de que é muito difícil encontrá-las. Sua aparição é vista como sinal de sorte e os visitantes que as encontram geralmente viram alvo de atenção de outros hóspedes quando retornam aos hotéis.

É possível dizer que as ariranhas contam com uma representação midiática que as classifica como bons animais e que há um mercado potencial para sua observação. Mas se a exposição na mídia é um fator decisivo para que elas entrem no campo de atenção dos turistas, não garante sozinha seu posicionamento como "produto" do turismo do Pantanal. Para tanto, as próprias ariranhas são atores essenciais. O animal que não aparece e que não tolera a presença humana não reúne condições para ser "ofertado" em um pacote. O surgimento de grupos de animais que aceitam a proximidade humana, conforme identificamos nesta pesquisa, é um componente importante no posicionamento das lontras gigantes como espécie carismática. Afinal, a maneira como se dá a experiência de proximidade é determinante na circulação de informações que os turistas vão promover sobre o passeio.

Contudo, esses encontros ainda escondem desafios éticos e potenciais conflitos. À primeira vista, ser uma atração turística pode lhes garantir uma maior rede de proteção. Por exemplo, como atores do turismo, as onças-pintadas de Porto Jofre rendem muitos dividendos financeiros para a população local e, por isso, são defendidas até

\footnotetext{
${ }^{4}$ The place of good animals, whether humam or nonhuman, is clear in the social order. They participate as "decent citizens" of a sort by being trustworthy, predictable, and obediente in their given roles [Tradução nossa].
} 
mesmo pelos donos de fazendas, seus tradicionais "inimigos" (BAPTISTELLA, 2020). Mas para se consolidar como espécie carismática do turismo é preciso que o animal seja totalmente submisso, ou conforme Arluke e Sanders (1996), seja bom. Onças-pintadas, jacarés-do-pantanal e tuiuiús observados durante a fase de campo apresentam um comportamento passivo em relação aos humanos, se prestando não apenas à observação, mas também às fotos e vídeos tão importantes para os visitantes. São animais que os guias e operadores de turismo chamam de habituados e, pelo menos no caso das onçaspintadas, é possível afirmar que tal processo, em algum momento, envolveu a ceva.

O problema é que tal prática é extremamente prejudicial para os animais. Conforme Paschoal (2019), animais cevados podem ficar dependentes, abandonando a busca natural por alimentos. Outro risco citado pelo autor é que ao associar humanos à comida, um animal pode atacá-los quando a oferta for negada. Temos aí também uma situação de inegável vulnerabilidade para as outras espécies, visto que não é possível controlar a aproximação de pessoas mal intencionadas. Conforme um dos guias entrevistados, um animal que não teme humanos tem mais chance de se tornar vítima de caçadores ou de maus tratos.

A ceva de ariranhas foi confirmada por pelo menos dois guias entrevistados. Eles afirmaram ainda que ela é praticada por pescadores, e também por alguns profissionais do turismo - pelo menos um deles é bastante famoso na internet justamente por vídeos em que aparece oferecendo peixes para os mustelídeos. Um dos informantes admitiu que conhecia casos de pessoas que ofereciam alimento para atrair os mustelídeos e que havia até mesmo animais que entravam em barcos. Além disso, foi possível constatar que para a maioria dos turistas quanto mais próximo do animal, melhor. O problema é que tal proximidade tende a incomodar os animais e o estresse pode provocar acidentes nos quais, certamente, será levado em conta preponderantemente o bem-estar humano. Nesse sentido, existe o risco de as ariranhas voltarem para o posto de feras ameaçadoras.

Durante uma das atividades de campo, recebemos o relato de que uma ariranha havia sido morta após entrar numa embarcação. A mesma informação chegou a outros pesquisadores a partir de fontes confiáveis. Contudo, havia duas versões. Na primeira,

\footnotetext{
${ }^{5}$ Os conflitos entre fazendeiros e onças-pintadas se dão pela ocorrência de predação de gado pelos grandes felinos. as em Porto Jofre, os lucros advindos da observação justificam sua proteção. Um estudo realizado por Tortato et al. (2017) com operadores de turismo na área de Porto Jofre-MT demonstrou que a renda promovida com o turismo de jaguares representa 56 vezes mais que o dano hipotético causado por predação a rebanhos. Segundo levantamento feito em sete hotéis da região, o gasto médio diário de um turista varia entre US\$150 e US\$900, dependendo do estabelecimento. A pesquisa também mostra que $80 \%$ dos turistas entrevistados concordariam em pagar uma taxa de proteção aos grandes felinos, que seria utilizada para compensar as perdas de fazendeiros.
} 
o animal foi morto porque assustou o humano, que com medo lhe desferiu várias pauladas. Na outra, teria sido atraída por um peixe e morta a facadas, apenas porque $\mathrm{o}$ humano quis matá-la. De toda forma, a fragilidade delas diante desse contato mais próximo com humanos fica evidenciada.

\section{Considerações}

Quantos papéis as ariranhas já viveram até aqui. Coexistiram no imaginário do século passado tanto como animais temidos pela ferocidade, quanto como bichos de estimação exóticos. Foram commodities do mercado de peles. Hoje, assim como as onças-pintadas, também estão encontrando uma nova persona. Se as reportagens de TV do passado as retratavam apenas como animais agressivos e territorialistas, agora são pintadas com cores mais amigáveis e sua complexa organização social é valorizada. Sua contrapartida no mundo real, parece completar esse ângulo de representação, na medida em que os animais estão sendo visualizados com mais frequência, relativamente próximos e, aparentemente, confortáveis com os humanos. É notável que para os turistas mais novos as ariranhas sejam até mesmo comparadas a cachorros, bichos de pelúcia e consideradas fofas. Durante o trabalho de campo, foram muitas as manifestações de desejo de brincar e até mesmo "morder" os animais.

Talvez não haja ainda um público específico para ariranhas, talvez a falta de garantias mais concretas de aparição dos animais inviabilize futuramente o que hoje parece um segmento turístico promissor em torno dos mustelídeos - inclusive porque não é possível precisar ainda o impacto dos incêndios florestais sobre as populações de ariranhas no Pantanal. Isso pode ser bom e ruim ao mesmo tempo. Conforme o biólogo Fernando Tortato, especialista em onças-pintadas, explicou em entrevista, para as ariranhas a proximidade dos barcos seria muito mais estressante do que para os grandes felinos, porque elas não têm a opção de se afastar (Caderno de Campo, fevereiro de 2020).

A bióloga Caroline Leuchtenberger confirmou o problema. As lontras gigantes estão pressionadas territorialmente e a presença dos turistas provoca estresse. No entanto, elas acabam por tolerar a situação, por falta de alternativa. Assim, é patente que estariam mais confortáveis sem a nossa presença. Por outro lado, sua ascensão como produto turístico pode ajudar a consolidá-las como uma espécie carismática, girando a tão falada roda da preservação em função dos lucros advindos do turismo. Hoje, os turistas expressam pouco temor em relação a elas, e sua avaliação geral é positiva. Alcançaram o status de bons animais. Diante de vídeos de ariranhas entrando em barcos 
para pegar peixes ou se aproximando de embarcações repletas de visitantes que demonstravam grande empolgação, perguntei à pesquisadora Caroline se 0 comportamento desses animais - antes avessos ao contato com humanos - estava mudando:

Isso é uma percepção, a gente não mensurou isso ainda, né? Mas a percepção é de que em áreas com muita, muita circulação de barcos e onde a população parece já ter estabilizado, já chegado na capacidade de suporte, ou seja, elas não têm mais para onde fugir, então os grupos, eles ficam na área e eles têm que aturar aquele monte de barco. Então, elas vão se acostumando com aquele movimento. Mas o que eu tenho acompanhado agora no Jofre, (é que) elas aturam até certo limite. Tem um momento assim em que elas saturam daquele estresse todo, e elas começam a se tornar agressivas também. Então, claro que o bicho, o comportamento natural dele seria fugir. Como não tem para onde fugir, por que está cheio de ariranha, ela vai tentar aturar até onde ela consegue. Mas é claro que tem situação com filhotes, (em que) elas vão ficar um pouco mais estressadas. Ano passado, eu vi uma sequência de barcos se aproximando de um grupo e elas tranquilas. Agora, chegou o quinto barco e se aproximou, assim, dois metros mais perto do que os outros, elas ficaram muito, muito agressivas. Existe um limiar que varia de cada grupo e varia do histórico dos acontecimentos de antes disso, né? A maioria dos barcos não tem conhecimento disso, de que está estressando. (Caderno de Campo, fevereiro de 2020).

$\mathrm{O}$ comportamento das ariranhas vai se adaptando à realidade em que vivem. As grandes lontras que interagem com guias podem jamais ter a intenção de machucar qualquer um deles. O que aconteceria, no entanto, se o animal mordesse alguém? Se algum dia, uma ariranha acordasse num daqueles dias que chamamos de "ruins" e decidisse se expressar com uma reação mais agressiva? Ou se um dia ela estivesse especialmente estressada, cansada ou até mesmo faminta, e acabasse levando a ponta dos dedos do guia além do peixe que o profissional lhe ofereceu? Será que o animal receberia algum tipo de tolerância? Quais os efeitos de um acidente em relação à espécie como um todo? Para Caroline, a ceva só tem aspectos negativos:

Para qualquer espécie silvestre, a ceva não é legal, porque em algum momento o animal vai mostrar seu instinto natural e aí vai acontecer algum acidente, e a gente vai voltar a ter uma imagem negativa da espécie. É o risco da gente perder tudo isso que a gente está construindo, [de estarmos] voltando a dar um valor positivo para a espécie. Em uma situação de ceva, qualquer coisinha que acontecer, qualquer acidente que acontecer, a gente vai voltar a ter uma imagem negativa da 
espécie e para construir aquilo tudo de novo vai ser muito difícil. A gente pode admirar sem precisar tocar, é muito mais seguro para os dois, garante uma sustentabilidade. (Caderno de Campo, fevereiro de 2020).

A questão das interações negativas é que a conta, quase sempre, é paga apenas pelos bichos. Na Ilha Fraser, na Austrália, a presença de dingos, um tipo de cão selvagem, é um grande atrativo turístico. Conforme Burns (2016), as interações entre os animais humanos e não humanos no local não são sempre positivas. Os cachorros roubam alimentos dos campings e mordem pessoas. Inclusive, uma criança morreu em 2001, após ser atacada por dois dingos jovens. A primeira ação da agência governamental responsável pela área foi matar os animais que frequentavam áreas com presença de humanos ou que eram identificados como "problemáticos". É de se imaginar o que aconteceria num caso similar no Pantanal, por exemplo.

Por um lado, quanto mais próximas, mais admiradas são as ariranhas. Parte dos turistas entrevistados considerava que a observação é suficiente e a ceva, desnecessária. Um número maior desconhecia a questão da ceva e vários se mostravam interessados em tocar/manipular os animais. A proximidade, no entanto, era ponto pacífico. Quanto mais perto do animal, mais completa a experiência. Contudo, comportamentos irresponsáveis colocam a espécie em situação de vulnerabilidade. As ariranhas podem passar à posição de "demônios" muito rapidamente apenas por expressarem seu comportamento natural. Os animais que encontramos pouco sinalizaram agressividade, o que lhes garantiu o título de "fofinhos". Mas tal percepção pode mudar muito rapidamente. Por isso, se vivemos uma era em que a representação midiática já começa a fazer mais justiça à complexidade das vidas dos animais não humanos, ainda é preciso que o turismo se articule de forma a criar normas e condutas que incluam o respeito aos animais não humanos.

\section{Almost famous (?): The giant OTTER AS A CHARISMATIC SPECIES IN TOURISM}

ABSTRACT: This article aims to analyze the condition of the giant otter (Pteronura brasiliensis) as a charismatic species in tourism in the North Pantanal, Brazil, from its media representation and the tourists' perception about the species. Based on the Content Analysis methodology and an interdisciplinary theoretical approach, we analyzed the representation of these animals in television documentaries about Pantanal. Such evidence was articulated with the data obtained in a field research, in which ethnographic techniques were used based on the theoretical reference of multi- 
species ethnography. We conclude that the otters are positively represented in the media, but they are still fragile when it comes to their participation in tourist activities, especially given the possibility of conflicts with humans.

KEYWORDS: Animal studies. Socio-zoological scale. Communication and culture.

\section{(¿) Casi famosas (?): LA NUTRIa gigante COMO ESPECIE CARISMÁTICA EN EL TURISMO}

RESUMEN: Este artículo tiene como objetivo analizar la condición de la nutria gigante (Pteronura brasiliensis) como una especie carismática en el turismo del Pantanal Norte a partir de su representación mediática y de la percepción de la especie por parte de los turistas. Basándonos en la metodología de Análisis de Contenido y en un enfoque teórico interdisciplinario, analizamos la representación de estos animales en los documentales de televisión sobre el Pantanal. Esas evidencias se articularon con datos obtenidos en una investigación de campo, en la que se utilizaron técnicas etnográficas basadas en el marco teórico de la etnografía multiespecies. Concluimos que las nutrias están representadas positivamente en los medios, pero que aún son frágiles en lo que respecta a su participación en actividades turísticas, especialmente ante la posibilidad de conflictos con los humanos.

PALABRAS CLAVE: Nutria gigante. Comunicación y cultura contemporáneas. Escala socio-zoológica. Estudios con animales. Pantanal.

\section{REFERÊNCIAS}

ARLUKE, Arnold; SANDERS, Clinton. Regarding animals. Philadelphia: Temple University Press, 1996.

BAPTISTELLA, Eveline. Animais não humanos e humanos no turismo do pantanal matogrossense: da representação midiática ao encontro. Orientadora: Juliana Abonizio. 2020. 414f. Tese (Doutorado em Estudos de Cultura Contemporânea). Programa de Pós-Graduação em Estudos de Cultura Contemporânea, Universidade Federal de Mato Grosso, 2020.

BAPTISTELLA, Eveline. A representação dos animais na imprensa: uma proposta de reflexão ética. Comunicação, Cultura e Sociedade, Tangará da Serra, v.8, n.8, p.3 - 21, 2017-2018.

BARDIN, Lawrence. Análise de conteúdo. São Paulo: Edições 70, 2016. 
BAUMAN, Zygmunt. Vida para consumo: a transformação das pessoas em mercadoria. Rio de Janeiro: Jorge Zahar Editor, 2008.

BEKOFF, Mark. A vida emocional dos animais: alegria, tristeza e empatia nos animais: um estudo científico capaz de transformar a maneira como os vemos e tratamos. São Paulo: Cultrix, 2010.

BEKOFFE, Mark; PIERCE, Jessica. Wild Justice: The Moral Lives of Animals. University of Chicago Press: 2009.

BURNS, Georgette. Animals as tourism objects: ethically refocusing relationships between tourists and wildlife. In: MARKWELL, Kevin (org.). Animals and tourism: understanding diverse relationships. Bristol: Channel View Publications, 2016.

COSTA, Maria de Fátima. A história de um país inexistente: o Pantanal entre os séculos XVI e XVIII. São Paulo: Estação Liberdade, 1999.

COSTA, Susana. Letting people speak: the importance of local's attitudes for effective conservation programmes. Journal of Primatology, v.2, n.2, 2016.

DARWIN, Charles. A expressão das emoções no homem e nos animais. São Paulo: Companhia das Letras, 2009.

DEMELLO, Margo. Animals and Society: an introduction to human-animal studies. Nova Iorque: Columbia University Press, 2012.

FRANCO, José Luiz de Andrade; DRUMMOND, José Augusto; GENTILE, Chiara; AZEVEDO, Aldemir Inácio de. Biodiversidade e ocupação humana do Pantanal matogrossense: conflitos e oportunidades. Rio de Janeiro: Garamond, 2013.

GLOBO REPÓRTER Expedição ao Pantanal. Produção: Rede Globo de Televisão. Rio de Janeiro: Rede Globo de Televisão, 2017. 42 min., son. color.

GLOBO REPÓRTER Pantanal. Produção: Rede Globo de Televisão. Rio de Janeiro: Rede Globo de Televisão, 2011. 42 min., son. color.

HERSCOVITZ, Heloiza. Análise de conteúdo em jornalismo. In: LAGO, Cláudia; BENETTI, Márcia. Metodologia da pesquisa em jornalismo. Petrópolis, RJ: Vozes, 2007, p.123-142.

ICMBio. Livro Vermelho da Fauna Brasileira Ameaçada de Extinção: Volume I. 1. ed. Brasília, DF: ICMBio/MMA, 2018. Disponível em: https://www.icmbio.gov.br/portal/images /stories/comunicacao/publicacoes/publicacoes-diversas/livro_vermelho_2018_vol1.pdf. Acesso em: 22 out. 2020.

KING, Barbara. O que sentem os animais? Rio de Janeiro: Odisseia, 2014.

KIRKSEY, Eben; HELMREICH, Stefan. The emergence of multispecies ethnography. Cultural Anthropology, v. 25, n.4, p.545 - 576, 2010.

LESTEL, Dominique. As origens animais da cultura. Lisboa: Instituto Piaget, 2001. 
LINDEN, Eugene. The parrot's lament. Nova Iorque: Plume Books, 1999.

MARTÍN-BARBERO, Jesús. Dos meios às mediações: comunicação, cultura e hegemonia. Rio de Janeiro: Editora UFRJ, 2003.

MITSCH, W.; GOSSELINK, S. Wetlands. Canadá: Wiley \& sons, 2007.

MOTTA, Luiz Gonzaga. Análise pragmática da narrativa jornalística. In: LAGO, Cláudia; BENETTI, Márcia. Metodologia da pesquisa em jornalismo. Petrópolis, RJ: Vozes, 2007, p.143- 167 .

NICHOLS, Bill. Introdução ao documentário. São Paulo: Papirus, 2012.

PANTANAL DAS águas. Direção: Lawrence Wahba e Haroldo Palo Jr. Produção: National Geographic Channel. São Paulo: National Geographic Channel, 2012. 44 min, son., color.

PANTANAL SELVAGEM. Direção: Lawrence Wahba e Haroldo Palo Jr. Produção: National Geographic Channel. São Paulo: National Geographic Channel, 2012. 44 min, son., color.

PASCHOAL, Fábio. Entenda a diferença entre habituação e ceva de onças-pintadas. Onçafari, Campo Grande, 17 jan. 2019. Disponível em: https://oncafari.org/2019/01/17/habituacao-Xceva-de-oncas-pintadas/. Acesso em: 07 fev. 2020.

PAULA, Rogério; BOULHOSA, Ricardo. Caracterização dos conflitos: aspectos socioculturais e impactos econômicos. In: CAVALCANTI, Sandra Maria Cintra; PAULA, Rogério Cunha de; GASPARINI-MORATO, Rose Lílian (org.). Conflitos com mamíferos carnívoros: uma referência para o manejo e a convivência. Brasília: Instituto Chico Mendes de Conservação da Biodiversidade, 2015.

REY, Marcos. O roteirista profissional: televisão e cinema. São Paulo: Ática, 1989.

RODRIGUES, Livia; LEUCHTENBERGER, Caroline; SILVA, Vania Carolina Fonseca da. Avaliação do risco de extinção da Ariranha Pteronura brasilienensis (Zimmermann, 1780) no Brasil. In: Instituto Chico Mendes de Conservação da Biodiversidade (org.). Livro Vermelho da Fauna Brasileira Ameaçada de Extinção: Volume II - Mamíferos. Brasília: ICMBio, 2018 .

SERAFIM, José. Televisão e documentário: afinidades e desacertos. In: GOMES, Itânia Maria (Org.). Televisão e realidade. Salvador: EDUFBA, 2009.

SOUZA, José Aronchi. Gêneros e formatos na televisão brasileira. São Paulo: Summus, 2004.

SÜSSEKIND, Felipe. Sobre a vida multiespécies. Revista do Instituto de Estudos Brasileiros, n.69, p.159 -178, abr. 2018.

THOMPSON, John B. A mídia e a modernidade: uma teoria social da mídia. Petrópolis, RJ: Vozes, 2011.

TORTATO, Fernando R.; IZZO, Thiago J.; HOOGESTEIJN Rafael; PERES, Carlos A. The numbers of the beast: valuation of jaguar (Panthera onca) tourism and cattle depredadation in 
the Brazilian Pantanal. Global ecology and conservation, v. 11, p.106-114, jul. 2017.

Disponível em: https:/www.sciencedirect.com/science/article/pii/S2351989417300501\#!. Acesso em: 21 out. 2020.

TSING, Anna. Margens indomáveis: cogumelos como espécies companheiras. Ilha, v.17, n.1, p.177-201, jan/jul. 2015.

URRY, John; LARSEN, Jonas. The tourist gaze 3.0. Nottingham: Sage, 2011.

VIDIGAL, Lucas. Morte de sargento que salvou menino no Zoo completa 40 anos. Correio Brasiliense. Disponível em:

https://www.correiobraziliense.com.br/app/noticia/cidades/2017/08/31/interna_cidadesdf,6225 36/morte-de-sargento-que-salvou-menino-no-zoo-completa-40-anos.shtml. Acesso em 17 jul. 2020 .

WALL, Frans de. A era da empatia. São Paulo: Cia. das Letras, 2010.

Recebido em 20/08/2020.

Aprovado em 22/09/2020. 